\title{
The Positive Allosteric Modulator Morantel Binds at Noncanonical Subunit Interfaces of Neuronal Nicotinic Acetylcholine Receptors
}

\author{
Seungmae Seo, Jonathan T. Henry, Amanda H. Lewis, Nan Wang, and Mark M. Levandoski \\ Department of Chemistry, Grinnell College, Grinnell, Iowa 50112
}

We are interested in the positive allosteric modulation of neuronal nicotinic acetylcholine (ACh) receptors and have recently shown that the anthelmintic compound morantel potentiates by enhancing channel gating of the $\alpha 3 \beta 2$ subtype. Based on the demonstration that morantelelicited currents were inhibited by the classic ACh competitor dihydro- $\beta$-erythroidine in a noncompetitive manner and that morantel still potentiates at saturating concentrations of agonist (Wu et al., 2008), we hypothesized that morantel binds at the noncanonical $\beta 2(+) /$ $\alpha 3(-)$ subunit interface. In the present study, we created seven cysteine-substituted subunits by site-directed mutagenesis, choosing residues in the putative morantel binding site with the aid of structural homology models. We coexpressed the mutant subunits and their respective wild-type partners in Xenopus oocytes and characterized the morantel potentiation of ACh-evoked currents, as well as morantel-evoked currents, before and after treatment with a variety of methanethiosulfonate (MTS)-based compounds, using voltageclamp recordings. The properties of four of the seven mutants, two residues on each side of the interface, were changed by MTS treatments. Coapplication with ACh enhanced the extent of MTS modification for $\alpha 3 \mathrm{~A} 106 \mathrm{C} \beta 2$ and $\alpha 3 \beta 2 \mathrm{~S} 192 \mathrm{C}$ receptors. The activities of two mutants, $\alpha 3 \mathrm{~T} 115 \mathrm{C} \beta 2$ and $\alpha 3 \beta 2 \mathrm{~T} 150 \mathrm{C}$, were dramatically altered by MTS modification. For $\alpha 3 \beta 2 \mathrm{~T} 150 \mathrm{C}$, while peak current amplitudes were reduced, potentiation was enhanced. For $\alpha 3 \mathrm{~T} 115 \mathrm{C} \beta 2$, both current amplitudes and potentiation were reduced. MTS modification and morantel were mutually inhibitory: MTS treatment decreased morantel-evoked currents and morantel decreased the rate of MTS modification. We conclude that the four residues showing MTS effects contribute to the morantel binding site.

\section{Introduction}

Neuronal nicotinic acetylcholine receptors (nAChRs) are a diverse family of ligand-gated ion channels, distributed throughout the nervous system. Although we ultimately want to understand the function of $\mathrm{nAChRs}$ in normal physiology, these receptors are perhaps of greater interest currently because of their putative roles in neurological disorders (Paterson and Nordberg, 2000). Some known nicotinic ligands are already in clinical use [e.g., galantamine for cognitive enhancement in Alzheimer's patients (Birks, 2006) and varenicline in smoking cessation (Siu and Tyndale, 2007)]. However, the prevalence and complexity of neuropathies possibly involving nAChRs demands further development of nicotinic ligands (Jensen et al., 2005).

Decades of biochemical study, including recent crystallographic insight, have elucidated the structure of the nAChR ligand binding site (Arias, 2000; Sine, 2002). Five homologous subunits are arranged around the central ion pore with pseudo- $\mathrm{C}_{5}$ symmetry (Unwin, 2005), resulting in as many as five unique interfaces depending on the stoichiometry and order of

\footnotetext{
Received April 19, 2009; revised May 19, 2009; accepted May 31, 2009.

This work was supported by National Institutes of Health Academic Research Enhancement Award Grant R15 NS043163-01A1 and Research Corporation Cottrell Award CC5765. We thank Dr. Steven Sine and anonymous reviewers for critical comments on this manuscript and Dr. Michael Leone for consultation on the clinical literature.

Correspondence should be addressed to Mark M. Levandoski, Department of Chemistry, 11168 th Avenue, Grinnell College, Grinnell, IA 50112. E-mail: levandos@grinnell.edu.

DOI:10.1523/JNEUROSCI.1859-09.2009

Copyright $\odot 2009$ Society for Neuroscience $\quad$ 0270-6474/09/298734-09\$15.00/0
}

the subunits. Residues of the (+) side of an $\alpha$ subunit and the (-) side of the neighboring subunit comprise the canonical (agonist/ competitive antagonist) site. A major determinant of this binding site is a system of five aromatic residues that stabilize bound ligands through $\pi$-cation interactions with the quaternary ammonium group of $\mathrm{ACh}$, or a protonated amine group of the wide variety of plant alkaloid ligands (Karlin, 2002). Structure-activity analyses of diverse compounds (for review, see Romanelli and Gualtieri, 2003), coupled with new crystal structures (Celie et al., 2004; Hansen and Taylor, 2007) and modeling of subtypes (Sallette et al., 2004), promise an unprecedented understanding of ligand specificity in this system, leading to rational design.

Less well understood are the binding sites of noncompetitive nicotinic ligands, although interest in these compounds is growing (Bertrand and Gopalakrishnan, 2007). Quite diverse species, from inorganic cations (Hsiao et al., 2006; Moroni et al., 2008) through steroids (Curtis et al., 2002) and anesthetics (Nirthanan et al., 2008) to amines (Akk and Steinbach, 2005; Arias et al., 2006), alter nAChR activity, perhaps indicating diverse modes of modulation. In addition, the recent increase in reported $\mathrm{nAChR}$ allosteric modulators as lead compounds, such as PNU-120596 (Hurst et al., 2005) and NS1738 (Timmermann et al., 2007), underscores the need for further study of modulator mechanisms and binding sites.

We recently demonstrated that morantel (Mor) potentiates $\alpha 3 \beta 2 \mathrm{nAChRs}$ by enhancing channel gating, leading to increased frequency and more bursting of single-channel events (Wu et al., 
2008). Because Mor potentiates in the presence of saturating agonist concentrations and is noncompetitively inhibited by a competitive antagonist, we concluded that Mor potentiates noncompetitively.

In this study, we used a substituted cysteine accessibility approach to test the hypothesis that Mor binds at the $\beta(+) / \alpha(-)$ interface of nAChRs. The effects on ACh-evoked currents by methanethiosulfonate (MTS) modification of cysteines unequivocally demonstrate that this noncanonical interface participates in nAChR allosteric behavior. More importantly, Mor and MTS reagents are mutually inhibitory, which supports our hypothesis that the $\beta(+) / \alpha(-)$ interface constitutes the Mor binding site. Our results have implications for rational design of cholinergic agents.

\section{Materials and Methods}

Chemicals and media. All reagents used, unless noted otherwise, were reagent grade and obtained from Sigma. MTS reagents were from Toronto Research Chemicals; the three used in this study were [2-(trimethyl-ammonium)ethyl]methanethiosulfonate bromide (MTSET), 2-aminoethylmethanethiosulfonate hydrobromide (MTSEA), and benzylmethanethiosulfonate (MTSBn). Mor, shown in Figure $1 C$, is 1,4,5,6-tetrahydro-1-methyl-2-(2-[3-methyl2-thienyl] ethenyl)pyrimidine, tartrate salt. Oocytes were maintained in Barth's medium [in mm: $88 \mathrm{NaCl}, 1.0 \mathrm{KCl}, 2.5 \mathrm{NaHCO}_{3}, 0.3$ $\mathrm{Ca}\left(\mathrm{NO}_{3}\right)_{2}, 0.41 \mathrm{CaCl}_{2}, 0.82 \mathrm{MgSO}_{4}, 15$ HEPES, 2.5 sodium pyruvate, $\mathrm{pH}$ 7.6] supplemented with $100 \mathrm{U} / \mathrm{ml}$ penicillin/streptomycin (Invitrogen) and $50 \mu \mathrm{g} / \mathrm{ml}$ gentamicin (Cambrex Bio Science). During recordings, oocytes were perfused with oocyte Ringer's medium (OR2; in mм: $115 \mathrm{NaCl}, 2.5 \mathrm{KCl}, 1.8 \mathrm{CaCl}_{2}, 10$ HEPES, pH 7.3).

Mutagenesis and RNA preparation. Wild-type rat $\alpha 3$ and $\beta 2$ subunits in pGEMHE-based vectors were a gift from C. W. Luetje (University of Miami, Miami, FL) and were prepared using standard procedures (cf. Levandoski et al., 2003). DNA mutations were made using the QuikChange temperature cycling method (Stratagene). Mutants were verified by sequencing in both directions of the entire extracellular domain using capillary electrophoresis of dye-detected, dideoxy-generated fragments. Unless noted otherwise in the context of another receptor subtype, all $\alpha 3$ and $\beta 2$ residue numbering follows that in the structure a3b2rr.pdb (Sallette et al., 2004); these position numbers are smaller by two compared with numbering used elsewhere in the literature, which discrepancy arises because of homology modeling based on a crystal structure of a protein of a different sequence. The cDNAs were linearized with a unique restriction enzyme and were made RNase free by phenolchloroform extraction. RNAs were synthesized from these cDNAs using the T7 kit from Ambion. RNAs were either diluted to $0.5 \mu \mathrm{g} / \mu \mathrm{l}$ in RNasefree water or kept as concentrated stocks of $\sim 1.5-3.5 \mu \mathrm{g} / \mu \mathrm{l}$ and stored at $-20^{\circ} \mathrm{C}$.

Oocyte preparation and injection. Xenopus laevis oocytes were prepared either from whole ovary tissue purchased directly from Nasco or harvested by survival surgery on oocyte-positive female frogs (also from Nasco), using procedures approved by the Grinnell College Institutional Review Board in accord with the National Institutes of Health guidelines. Following established procedures (Bertrand et al., 1991), mature stage $\mathrm{V}-\mathrm{VI}$ oocytes were prepared by collagenase treatment and manual selection and maintained at $16^{\circ} \mathrm{C}$ with daily exchanges of Barth's medium. Oocytes were typically injected with $46 \mathrm{nl}$ of $1: 1 \alpha: \beta$ mixtures of $0.5 \mu \mathrm{g} / \mu \mathrm{l}$ stocks using a Drummond Scientific Nanoject; occasionally, 1:1 ratios at the maximum mass of RNA possible (up to $\sim 150 \mathrm{ng}$ total) were injected to boost expression for certain mutant receptors. After a 2-3 d maintenance period allowing for receptor expression, currents could be recorded for up to $7 \mathrm{~d}$ more.

Voltage-clamp recording. We used a GeneClamp 500B amplifier and Digidata 1322A data acquisition system (Molecular Devices) to measure evoked currents from oocytes using the two-electrode voltage-clamp method; a subset of experiments were made using a Warner Instruments $752 \mathrm{C}$ amplifier. Perfusion and drug delivery was controlled with Warner
Instruments VC-6 solenoid valve systems. Recording electrodes had resistances of $\sim 0.5-4 \mathrm{M} \Omega$ when filled with $3 \mathrm{M} \mathrm{KCl}$. The voltage was clamped at $-60 \mathrm{mV}$, unless noted otherwise, and leak currents were usually in the range of -10 to $-50 \mathrm{nA}$. The changes in current with respect to the baseline in response to (typically) $5 \mathrm{~s}$ drug applications were recorded. Current responses were recorded using Clampex 9.2, and peaks were measured with Clampfit 9.2 (Molecular Devices). Between drug applications, oocytes were washed for at least $100 \mathrm{~s}$ with OR2.

We characterized ACh plus Mor concentration-response behavior of the mutant receptors across the micromolar to millimolar range, as well as their ACh and Mor potentiation. For purposes of comparison, we fit the Hill equation to concentration-response data for the mutant subtypes using Origin 7.5 (OriginLab). Unless noted otherwise, the measure of potentiation was a coapplication of $10 \mu \mathrm{M}$ Mor and ACh at approximately $\mathrm{EC}_{50}$ for that subtype. Evoked responses were quite stable; variation in the absolute peak current was only $5-10 \%$ and was random when giving three to four repeated challenges. In addition, over long recording times (15-60 $\mathrm{min})$ and multiple challenges (10-30), variation in peak current amplitudes for standard challenges (ACh, ACh plus Mor) repeated throughout the experiment (absent MTS treatment) was similarly small and random.

In experiments using MTS reagents, we followed established procedures (Karlin and Akabas, 1998); small aliquots of the reagent were dissolved in water and kept on ice before diluting to the working concentration in OR2 immediately before use in the experiment. Our standard MTS application was four $30 \mathrm{~s}$ continuous-flow applications of the reagent, separated by a $100 \mathrm{~s}$ wash, totaling $2 \mathrm{~min}$ of cumulative exposure. For longer exposures, the oocyte was perfused for $30 \mathrm{~s}$ with the reagent, followed by a static bath incubation with the reagent for the remaining time. In the MTSET kinetics experiments (see Fig. 6), oocytes were exposed to the reagent for increasingly longer periods, for cumulative exposures of $\geq 2 \mathrm{~min}$; between exposures, evoked responses were measured, with a $100 \mathrm{~s}$ wash before and after the challenge. For the MTSET plus $100 \mu \mathrm{M}$ Mor coapplication experiments, oocytes were preexposed to Mor for $15 \mathrm{~s}$ immediately preceding treatment. Responses were normalized to the control before MTSET applications. Fits to the exponential decay function $y=A \times \exp (-t / \tau)+B$ were also done with Origin.

\section{Results}

We demonstrated in previous work that Mor, an anthelmintic used widely against livestock infections (Martin, 1997), potentiates $\alpha 3 \beta 2$ nicotinic receptors by improving channel gating, and that it does so noncompetitively ( $\mathrm{Wu}$ et al., 2008). Given the structural homology of nicotinic subunits, in particular the conservation of several aromatic residues known to play a role in the canonical agonist binding site (Karlin, 2002; Sine, 2002), we postulated that the alternate interfaces of a heteropentameric nAChR formed possible ligand binding sites (Levandoski et al., 2003). As indicated in Figure 1, we targeted residues in the $\beta(+) / \alpha(-)$ interface for substitution with cysteine to probe these loci by covalent MTS modification, aiming to demonstrate that Mor acts via these sites. We chose conservative mutations (ser, thr, ala $\rightarrow$ cys) so as to preserve wild-type-like Mor potentiation to facilitate interpretation of MTS effects.

The sample data in Figure 2 illustrate that Mor potentiates nAChR currents and that MTS modification reduces these currents; these are the two key measurements used throughout this study. For the three subtypes shown, Mor greatly potentiates the response to the approximate $\mathrm{EC}_{50}$ concentration of $\mathrm{ACh}$; the control, pre-MTSET potentiation $\left(I_{\mathrm{ACh}+\mathrm{Mor}} / I_{\mathrm{ACh}}\right)$ (Fig. 2, left set of traces for each subtype) was $2.8,3.3$, and 4.5 for wild type, $\alpha 3 \beta 2 \mathrm{~T} 150 \mathrm{C}$, and $\alpha 3 \mathrm{~T} 115 \mathrm{C} \beta 2$, respectively. The 2 min exposure to $100 \mu \mathrm{M}$ MTSET (Fig. 2, arrows) failed to alter the responses of the wild-type $\alpha 3 \beta 2$. However, this treatment dramatically decreased the responses for the two mutants: the ACh-evoked current of the $\alpha 3 \beta 2 \mathrm{~T} 150 \mathrm{C}$ receptor was decreased relatively more 
than the response to coapplied $\mathrm{ACh}$ and Mor, which increased potentiation to 7.5 (from 3.3). In contrast, MTSET decreased $I_{\mathrm{ACh}+\text { Mor }}$ more than $I_{\mathrm{ACh}}$ for the $\alpha 3$ T115 $\beta 2$ receptor, such that potentiation was reduced to 2.8 (from 4.5). With a quaternary ammonium group, MTSET leaves behind a positive charge at the site of reaction. Given these large quantitative effects of chemical modification, we sought to demonstrate that perturbed ligand binding gives rise to changes in Mor potentiation.

\section{$\boldsymbol{\beta}(+) / \boldsymbol{\alpha}(-)$ interface mutants}

Potentiation is a sensitive function of both agonist and modulator concentrations (Levandoski et al., 2003; Wu et al., 2008). We therefore first measured the agonist concentration-response relationships for the series of mutants and fit the Hill equation to these data. Those parameters are given in Table 1. Most of the mutants have an $\mathrm{EC}_{50}$ for activation by $\mathrm{ACh}$ similar to wild-type $\alpha 3 \beta 2$, in the range of 20-70 $\mu \mathrm{M}$. Only $\alpha 3$ T $115 \mathrm{C} \beta 2$ and $\alpha 3 \mathrm{~S} 161 \mathrm{C} \beta 2$ have $\mathrm{EC}_{50}$ values up to fourfold greater than wild type. All mutants have Hill coefficients $n_{\mathrm{H}}<1$, indistinguishable from wild type; this apparent lack of cooperativity has been reported for rat and human $\alpha 3 \beta 2$ receptors (Cohen et al., 1995; Harvey and Luetje, 1996; Chavez-Noriega et al., 1997). Typically, the level of expression for the mutant receptors was equivalent to that for wild type, as indicated by similar peak current amplitudes evoked by an equieffective concentration of ACh (data in Fig. 2). Only $\alpha 3 \mathrm{~A} 106 \mathrm{C} \beta 2$ and $\alpha 3 \beta 2 \mathrm{~S} 148 \mathrm{C}$ receptors had $\sim 3$ - and 10-fold smaller currents than wild type, respectively. Collectively, these data suggest that changing these residues to cysteine alone does not greatly alter ACh activation in the receptors.

To compare across receptor mutants, we defined a standard test of potentiation as the current enhancement by $10 \mu \mathrm{M}$ Mor relative to the control response evoked by an ACh concentration approximately the $\mathrm{EC}_{50}\left(I_{\mathrm{ACh}+\mathrm{Mor}} / I_{\mathrm{ACh}}\right)$. Based on previous work with wild-type receptors (Wu et al., 2008), these conditions result in nearly maximal potentiation while avoiding open-channel block effects. Sample data of this sort are shown in Figure 2, and the collated data of these potentiation measures are given in Table 1. With the exception of $\alpha 3 \beta 2 S 148 \mathrm{C}$, all the mutant receptor responses were potentiated to the same degree as the wild type, in the range of 1.3-2.3; this may indicate that the substitution of cysteine in these positions alone does not perturb Mor effects.
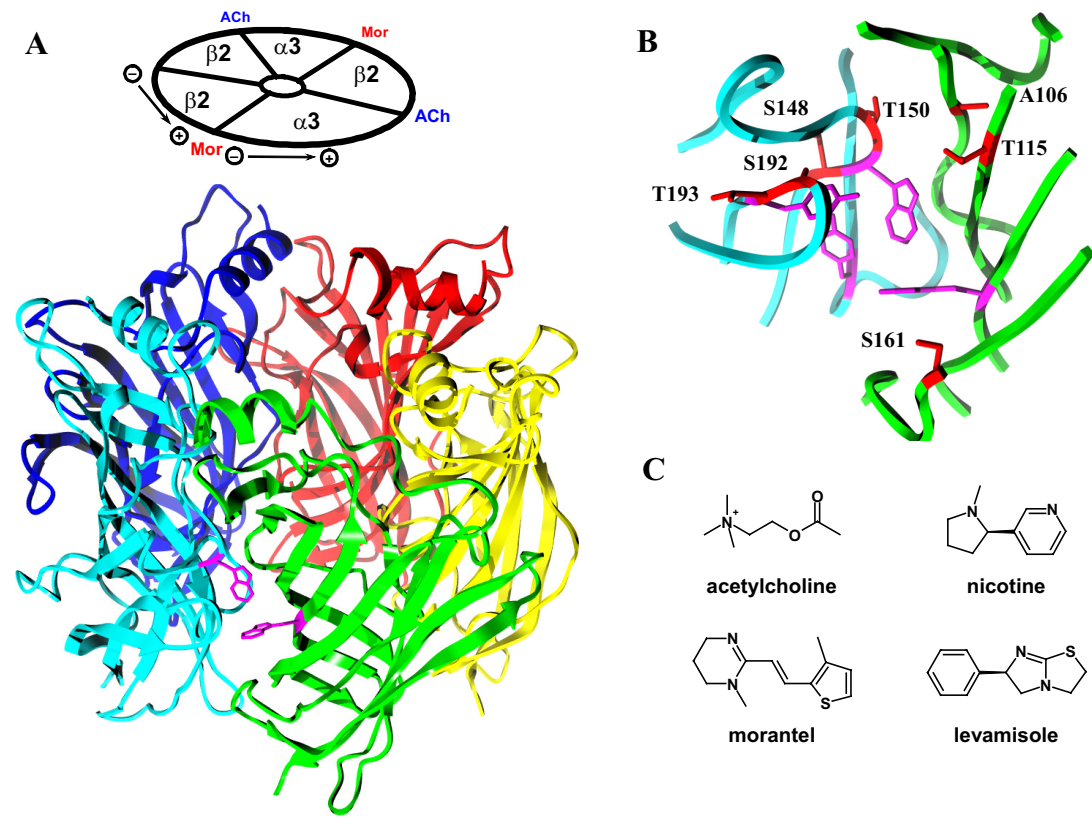

C

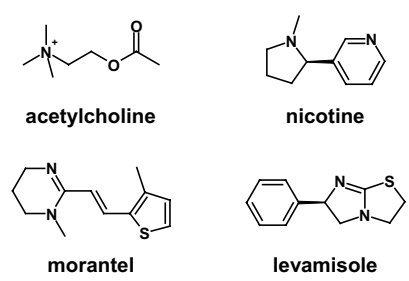

Figure 1. Targeting the putative modulator site. $\boldsymbol{A}$, The pentameric $(\alpha 3)_{2}(\beta 2)_{3} \mathrm{nAChR}$ has three types of subunit interfaces, including canonical agonist sites $[\mathrm{ACh} ; \alpha(+) / \beta(-)]$ and hypothesized modulator sites $[\mathrm{Mor} ; \beta(+) / \alpha(-)]$. The five subunits of the homology model of the rat $\alpha 3 \beta 2 \mathrm{nAChR}$ extracellular domain (Sallette et al., 2004) are given in different colors for clarity. $\boldsymbol{B}$, Residues near the $\beta(+) / \alpha(-)$ interface were selected for conservative cysteine substitution. These were $\beta 2 S 148, \beta 2 T 150$, $\beta 2 S 192, \beta 2$ T193; and $\alpha 3$ A106, $\alpha 3$ T115, $\alpha 35161$ (shown in red). The magenta residues $(\alpha 3$ W53, $\beta 2 Y 93, \beta 2 W 149$, and $\beta 2 Y 194)$ line a pocket at this interface and are homologous to conserved aromatic residues in the canonical binding site. $C$, The structures of two allosteric modulators of neuronal nAChRs and two canonical agonists are shown.
WT $\alpha 3 \beta 2$

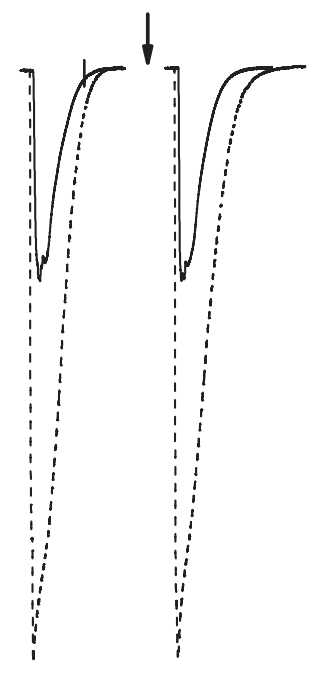

$\alpha 3 \beta 2 \mathrm{~T} 150 \mathrm{C}$

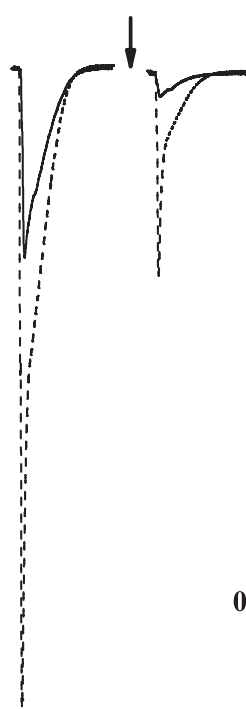

$\alpha 3 T 115 C \beta 2$
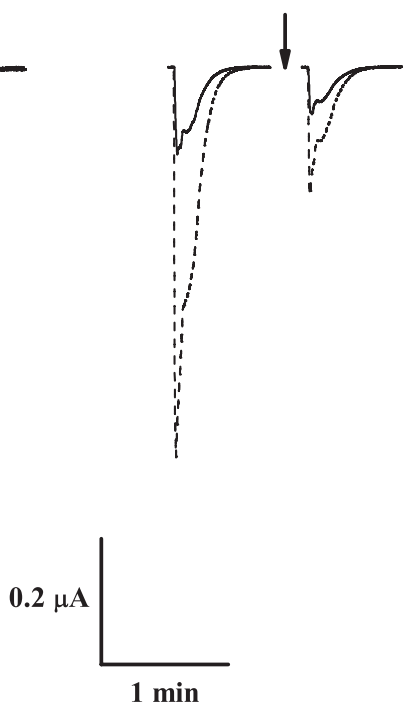

Figure 2. MTSET alters potentiation of cys-substituted nAChRs. Sample current traces for three separate oocytes expressing the indicated subunit combinations are shown. Solid traces are control responses evoked by ACh alone, and dashed traces (overlaid for space economy) are coapplications of that ACh concentration and $10 \mu \mathrm{m}$ Mor. The two sets of traces are before (left) and after (right) the standard MTS reagent treatment of four $30 \mathrm{~s}$ doses of $100 \mu \mathrm{m}$ MTSET, coapplied with ACh (arrows); in all cases, at least 100 s of washout preceded each challenge. The $A C h$ concentration was approximately $\mathrm{EC}_{50}$ for each subtype: $100 \mu \mathrm{m}$ for wild-type (WT) $\alpha 3 \beta 2$ and $300 \mu \mathrm{m}$ for $\alpha 3 \beta 2 \mathrm{~T} 150 \mathrm{C}$ and $\alpha 3 \mathrm{~T} 115 \mathrm{C} \beta 2$. In each experiment, the membrane potential was held at $-60 \mathrm{mV}$. For the data shown here, cRNAs defining the three subtypes were injected as the mixture of equal volumes $(\alpha: \beta)$ of $0.5 \mu \mathrm{g} / \mu \mathrm{l}$ stocks, $23 \mathrm{ng}$ total, our standard protocol.

\section{Effects of MTS reagents}

We next tested the effects of the thiol-specific reagent MTSET on the mutant receptors to probe whether these residues were important in Mor potentiation. After measuring control responses 
Table 1. ACh response and Mor potentiation characteristics

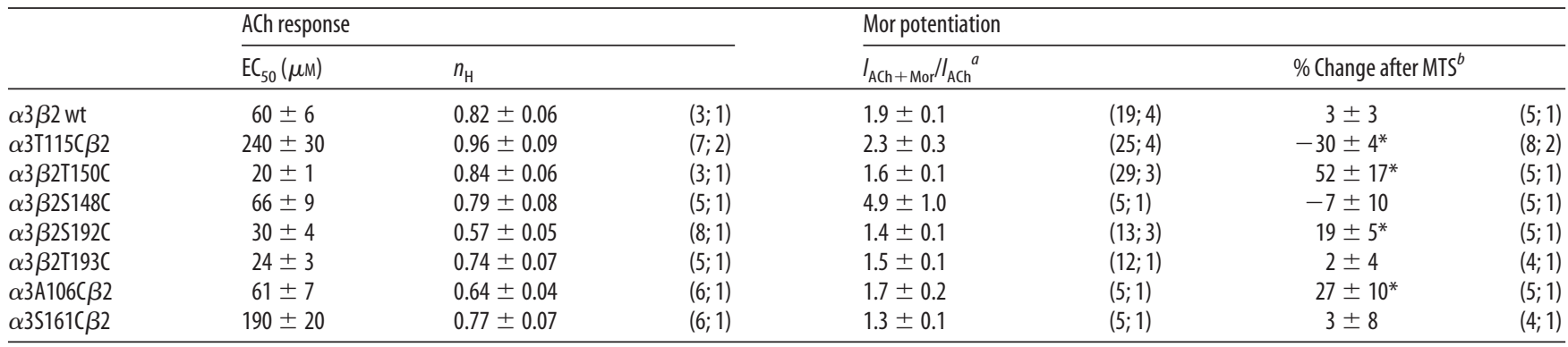

Values are means \pm SEM. In each experiment, the number of oocytes tested and the number of donors, respectively, are given in parentheses. wt, Wild type.

${ }^{a}$ The standard measure of potentiation used $[\mathrm{ACh}] \sim \mathrm{EC}_{50} \pm 10 \mu \mathrm{m}$ Mor.

${ }^{b}$ All experiments used $100 \mu \mathrm{M}$ MTSET. Treatment involved coapplying with ACh at the control concentration, except for $\alpha 3 \beta 2 T 150 C, \alpha 3 \beta 2 S 148 C$, and $\alpha 3 S 161 C \beta 2$, where the reagent was applied alone. Asterisks indicate the change in potentiation after treatment was statistically significant $(p<0.05)$ as measured by a paired comparison $t$ test.

to ACh and ACh plus Mor, oocytes were exposed to the MTS reagent for $2 \mathrm{~min}$. We typically tested both modification by MTSET alone and by coapplication with ACh. A summary of these experiments is given in Table 1.

Importantly, there was no effect of MTSET plus ACh coapplication on wild-type $\alpha 3 \beta 2$ receptors (Fig. 2, Table 1). The extracellular domains of $\alpha 3$ and $\beta 2$ subunits contain no cysteine residues that are not otherwise oxidized into the vicinal pair in the $\mathrm{C}$ loop or the cys-loop disulfide bonds. We also tested exposure to MTSET alone $(n=3)$, exposure to MTSEA alone $(n=5)$, and a longer incubation with higher MTSET concentration alone (10 $\min$ at $1 \mathrm{mM}$ vs $2 \mathrm{~min}$ at $100 \mu \mathrm{M} ; n=6$ ) on wild-type receptors (supplemental Table $1 A$, available at www.jneurosci.org as supplemental material). In modifying a cysteine residue, MTSEA leaves behind a primary amine group that should be positively charged at the $\mathrm{pH}$ of our experiments. In all these cases, there was no appreciable change in potentiation.

Three mutant receptors ( $\alpha 3 \beta 2 S 148 \mathrm{C}, \alpha 3 \mathrm{~S} 161 \mathrm{C} \beta 2$, and $\alpha 3 \beta 2$ T193C) were also unaffected by treatment with MTSET (Table 1). In addition to the experiments summarized there, we also tested $\alpha 3 \beta 2$ S148C against exposure to MTSEA alone $(n=3)$, $\alpha 3 \operatorname{S161C} \beta 2$ against a longer incubation with $\operatorname{MTSET}(n=5)$, and $\alpha 3 \beta 2$ T193C against MTSEA alone $(n=5)$. These challenges similarly failed to produce changes in Mor potentiation (supplemental Table 3C,E, F, available at www.jneurosci.org as supplemental material). Therefore, we did not study these mutant receptors further.

\section{Agonist enhances MTS reactivity}

As indicated in Table 1, MTS treatment significantly altered potentiation in four mutant receptors. In studying these four mutants further, we discovered that agonist coapplied with the MTS reagent can greatly increase the extent of modification. This result is shown in Figure 3. For both $\alpha 3 \mathrm{~A} 106 \mathrm{C} \beta 2$ and $\alpha 3 \beta 2 \mathrm{~S} 192 \mathrm{C}$, applying MTSET alone showed no change in potentiation outside of error ( $p=0.37$ and 0.21 , respectively in paired $t$ test). In contrast, coapplying MTSET and ACh increased potentiation for both, by 27 and $19 \%$ for $\alpha 3 \mathrm{~A} 106 \mathrm{C} \beta 2$ and $\alpha 3 \beta 2$ S192C, respectively. The sample traces for these experiments (Fig. 3, inset) reveal that the increase in potentiation arises from the combined decrease in $I_{\mathrm{ACh}}$ and increase in $I_{\mathrm{ACh}+\text { Mor }}$. We confirmed these results for $\alpha 3 \beta 2$ S192C in two other experiments using MTSEA alone (no effect) and coapplication of MTSET and $100 \mu \mathrm{M} \mathrm{ACh}$ (vs $30 \mu \mathrm{M}$ ACh in Fig. 3; increased potentiation) (supplemental Table $1 D$, available at www.jneurosci.org as supplemental material). Together, these results indicate that ACh can increase the rate of MTS modification and establish that the $\beta(+) / \alpha(-)$ in-

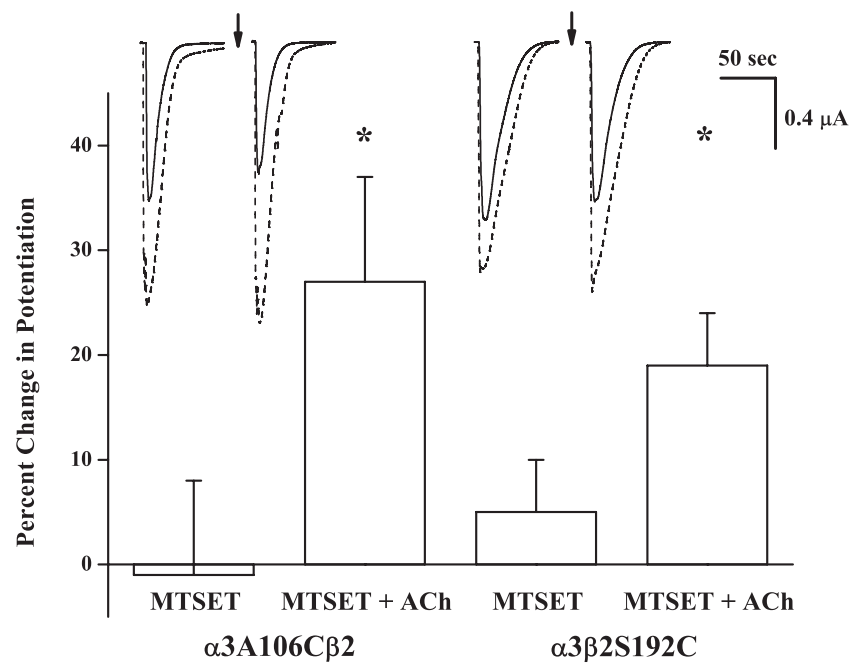

Figure 3. ACh increases MTSET modification. Potentiation $\left(I_{A C h+M o r} / I_{A C h}\right)$ was measured before and after four $30 \mathrm{~s}$ doses of $100 \mu \mathrm{m}$ MTSET separated by $100 \mathrm{~s}$ wash periods, using 100 $\mu \mathrm{M}$ ACh for $\alpha 3 \mathrm{~A} 106 \mathrm{C} \beta 2$ and $30 \mu \mathrm{M}$ ACh for $\alpha 3 \beta 2 \mathrm{~S} 192 \mathrm{C}$. The percentage change was then calculated. The treatment was MTSET either alone or coapplied with ACh at the control concentration. Data are the means \pm SEM for $n=5$ (1 donor). The asterisk indicates the change in potentiation after treatment was statistically significant $(p<0.05)$ as measured by a paired comparison $t$ test. Numerical data for these MTSET plus ACh experiments are also given in Table 1. The insets show sample data traces for the MTSET plus ACh measurements for $\alpha 3$ A106C $\beta 2$ (left) and $\alpha 3 \beta 2 S 192 C$ (right). Solid traces are control responses evoked by ACh alone, and dashed traces (overlaid for space economy) are coapplications of that ACh concentration and 10 $\mu \mathrm{m}$ Mor. The two sets of traces are before (left) and after (right) MTS reagent treatment of four 30 s doses of $100 \mu \mathrm{m}$ MTSET, coapplied with ACh (arrows); in all cases, at least 100 s of washout preceded each challenge.

terface is allosterically coupled to the canonical (agonist) binding site. Because the MTS effects on potentiation were large for the $\alpha 3$ T $115 \mathrm{C} \beta 2$ and $\alpha 3 \beta 2$ T $150 \mathrm{C}$ receptors (Fig. 2, Table 1 ) and their expression was most reliable, we chose to study them in greater detail.

\section{MTS modification perturbs $\alpha 3 \beta 2 \mathrm{~T} 150 \mathrm{C}$ receptor function}

The most striking feature of MTSET treatment on the $\beta(+)$ mutant $\alpha 3 \beta 2 \mathrm{~T} 150 \mathrm{C}$ is a large increase in potentiation (Figs. 2, 4). Figure 4 shows the results of two experiments designed to understand this effect in more detail. First, we measured the ACh concentration-response relationship before and after MTSET/agonist coapplication treatment (Fig. 4, gray symbols and dashed fitted curves). The treatment resulted in a 4.5 -fold decrease in potency and a $75 \%$ decrease in efficacy, as measured by the maximum response at high-ACh concentration. In a second experi- 


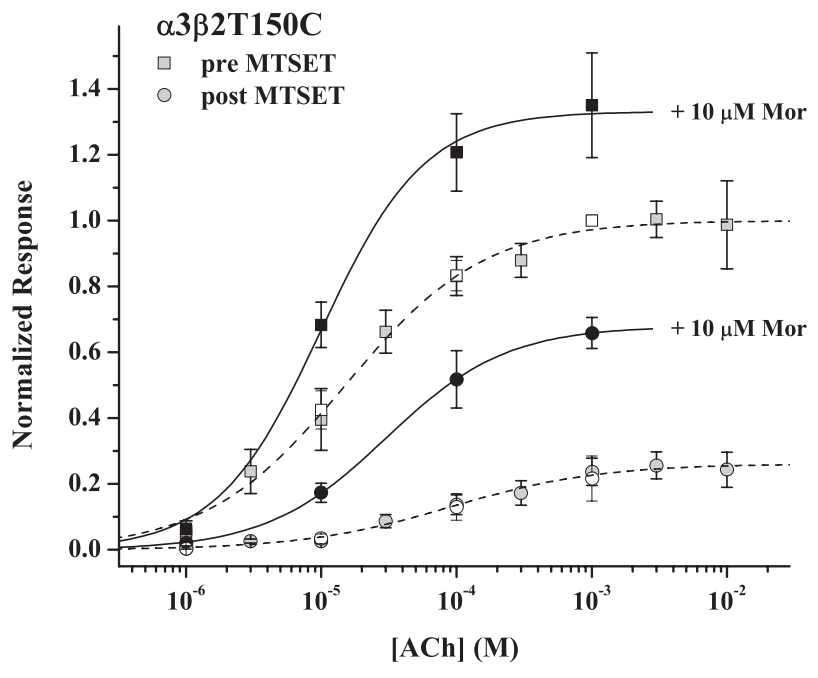

Figure 4. MTSET decreases potency and efficacy of $\alpha 3 \beta 2 \mathrm{~T} 150 \mathrm{C}$ receptors. Two separate experiments are shown, both of which used the treatment of $100 \mu \mathrm{m}$ MTSET and $200 \mu \mathrm{m} \mathrm{ACh}$ coapplied for $30 \mathrm{~s}$ four times separated by at least a $100 \mathrm{~s}$ wash. The first experiment (gray symbols) was a standard ACh concentration-response measurement, with fits to the Hill equation (dashed curves) characterized by the following $\left(\mathrm{EC}_{50}\right.$ in $\left.\mu \mathrm{M}, n_{\mathrm{H}}, E_{\mathrm{max}}\right)$ : pretreatment (gray squares), $20 \pm 1,0.84 \pm 0.06,1.00$; posttreatment (gray circles), $90 \pm 20,0.79 \pm 0.11$, $0.26 \pm 0.01$. The second experiment (filled and open symbols) used four ACh concentrations in the presence or absence of $10 \mu \mathrm{m}$ Mor. The fits to the Hill equation for the + Mor data sets (solid curves) are characterized by the following ( $\mathrm{EC}_{50}$ in $\mu \mathrm{M}, n_{H}, E_{\max }$ ): pretreatment (filled squares) $10 \pm 2,1.13 \pm 0.24,1.33 \pm 0.05$; posttreatment (filled circles), $30 \pm 1,0.98 \pm 0.02,0.68 \pm$ 0.01 . All responses were normalized to the ACh response at $1000 \mu \mathrm{m} . n=3$ for both experiments.

ment, potentiation as a function of ACh concentration $(1,10$, $100,1000 \mu \mathrm{M}$ ) (Fig. 4, pairs of open and filled symbols, solid fitted curves) was measured before and after MTSET treatment. In this case, the ACh/Mor concentration-response curve also shifted, but the decrease in potency was only threefold, and the decrease in efficacy was only $50 \%$. Given these differential shifts, we must carefully calculate the MTS effect on potentiation (supplemental Table $1 B$, available at www.jneurosci.org as supplemental material). Measured at approximately $\mathrm{EC}_{50}$, potentiation was 1.6 before treatment and 4.0 after treatment; measured at approximately $\mathrm{EC}_{75}$, potentiation was 1.5 before and 3.0 after. These results suggest that, despite a reduction in all evoked currents, MTS treatment of $\alpha 3 \beta 2$ T150C yields a receptor that may be potentiated better by Mor than the untreated receptor. Verifying this at a microscopic level (e.g., as increased Mor enhancement of channel opening rate after modification) will require singlechannel analysis.

\section{MTS modification perturbs $\alpha 3$ T115C $\beta 2$ receptor function} In addition to reducing all evoked currents (Figs. 2, 5), MTS treatment reduces Mor potentiation for the $\alpha(-)$ mutant $\alpha 3 \mathrm{~T} 115 \mathrm{C} \beta 2$ receptor. As demonstrated in Figure 5, coapplication of MTSET and ACh reduced $I_{\mathrm{ACh}}, I_{\mathrm{ACh}+\mathrm{Mor}}$, and potentiation to the same extent whether the ACh concentration was 30 $\mu \mathrm{M}$ ACh (approximately $\mathrm{EC}_{20}$ ) or $300 \mu \mathrm{M}$ ACh (approximately $\mathrm{EC}_{50}$ ). In other words, despite the magnitude of potentiation $\left(I_{\mathrm{ACh}+\mathrm{Mor}} / I_{30 \mu \mathrm{M} \mathrm{ACh}}=7.7 \mathrm{vs} I_{\mathrm{ACh}+\mathrm{Mor}} / I_{300 \mu \mathrm{M} \mathrm{ACh}}=2.2\right)$ and the relative current amplitudes each differing in the two experiments, the effect of MTS treatment was quantitatively the same. We confirmed this result by measuring the concentration-response relationship over the range $1 \mu \mathrm{M}$ to $10 \mathrm{~mm}$ ACh before and after MTSET treatment, finding that the potency was unchanged after

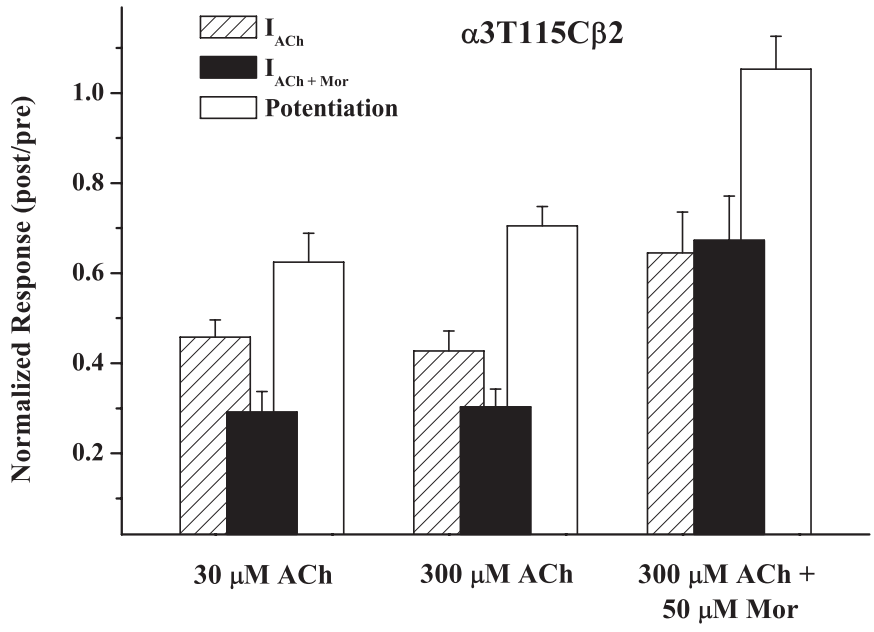

Figure 5. Mor blocks MTSET modification of $\alpha 3 \mathrm{~T} 115 \mathrm{C} \beta 2$ receptors. MTSET was coapplied to $\alpha 3 \mathrm{~T} 115 \mathrm{C} \beta 2$ receptors with $30 \mu \mathrm{m} \mathrm{ACh}, 300 \mu \mathrm{m}$ ACh, or $300 \mu \mathrm{m}$ plus $50 \mu \mathrm{m}$ Mor, in four $30 \mathrm{~s}$ doses separated by a 2 min wash. Paired comparisons of the potentiation measure gave $p=0.004(30 \mu \mathrm{m} \mathrm{ACh} ; n=5), p=0.002$ (300 $\mu \mathrm{m} \mathrm{ACh;} n=8)$, and $p=0.177$ (300 $\mu \mathrm{MACh}$ plus $50 \mu \mathrm{m}$ Mor; $n=6)$. Numerical data for the MTSET plus $300 \mu \mathrm{m}$ ACh experiments are also given in Table 1.

treatment, but the efficacy was reduced by $64 \pm 7 \%$ at saturating ACh concentrations (supplemental Fig. 1, available at www. jneurosci.org as supplemental material).

The third experiment in Figure 5 demonstrates that when 50 $\mu \mathrm{M}$ Mor was included with the MTSET/ACh coapplication, $I_{\mathrm{ACh}}$ and $I_{\mathrm{ACh}+\text { Mor }}$ were reduced significantly less than when Mor was absent $(p=0.018$ and $p=0.001$ for these two measures, respectively), and there was no change in potentiation (post/pre $=$ $1.05 \pm 0.07 ; n=6 ; p=0.17$ for paired comparison). This result indicates that Mor can inhibit MTS modification of $\alpha 3$ T115C $\beta 2$ receptors.

We also tested the effect of MTSBn and MTSEA on $\alpha 3 \mathrm{~T} 115 \mathrm{C} \beta 2$ receptors (data not shown). Treatment with $100 \mu \mathrm{M}$ MTSBn alone reduced both ACh- and ACh/Mor-evoked currents, by $29 \pm 9 \%(p=0.012)$ and $30 \pm 10 \%(p=0.036)$, respectively, resulting in no change in potentiation (post/pre $=$ $0.99 \pm 0.10 ; p=0.21$ for paired comparison; $n=9,4$ donors). In contrast, $100 \mu \mathrm{M}$ MTSEA did not reduce the ACh-evoked currents $\left(I_{\text {post }} / I_{\text {pre }}=1.08 \pm 0.08 ; p=0.43\right)$ but reduced the ACh/ Mor-evoked currents by $24 \pm 5 \%(p=0.001)$ and thereby the degree of potentiation by $26 \pm 6 \%(p=0.005 ; n=14,4$ donors $)$. Currents evoked by $100 \mu \mathrm{M}$ Mor alone were also reduced in these experiments, by $36 \pm 5 \%$. In summary, the effects of modification on the agonist and modulator responses for $\alpha 3 \mathrm{~T} 115 \mathrm{C} \beta 2$ receptors depend on the MTS reagent, and Mor-mediated currents are always reduced.

\section{ACh and Mor differentially alter MTS modification kinetics}

In most of our experiments, we used a fixed duration of MTS treatment to measure relative magnitudes of effects. However, we also studied the kinetics of MTS modification to verify that the fixed times were sufficient for complete reaction and to gain insight into the interaction of MTS reagents and Mor. Figure 6 shows the kinetics of MTSET modification of $\alpha 3$ T115C $\beta 2$ receptors, as measured by the reduction in ACh/Mor-evoked currents. The rate of reaction increased in the presence of ACh but decreased in the presence of Mor. These rates differ fourfold to fivefold, as indicated by the time constants of 34, 170, and $720 \mathrm{~s}$ for the series MTSET plus ACh, MTSET alone, and MTSET plus 


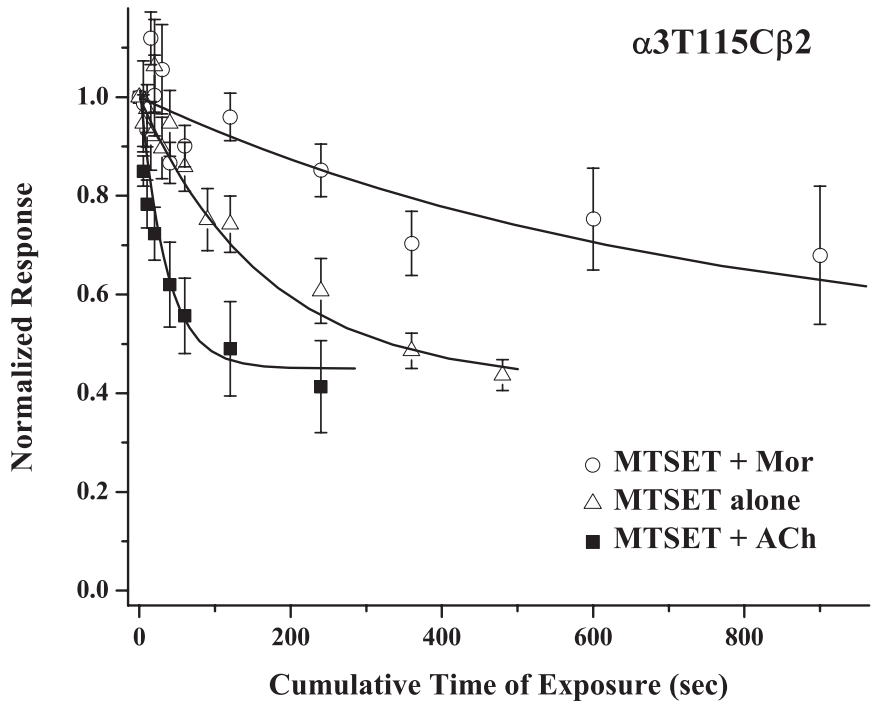

Figure 6. ACh and Mor alter MTSET kinetics in opposite directions. The response of $\alpha 3 \mathrm{~T} 115 \mathrm{C} \beta 2$ receptors to coapplied $300 \mu \mathrm{m} \mathrm{ACh}$ and $10 \mu \mathrm{m}$ Mor was measured as a function of cumulative time of exposure to $30 \mu \mathrm{m}$ MTSET. Oocytes were washed for 100 s after either MTSET exposure or response challenge. Three conditions were tested: a control of MTSET application alone (triangles), MTSET coapplied with $300 \mu \mathrm{M}$ ACh (squares), and MTSET coapplied with 100 $\mu \mathrm{m}$ Mor (circles). In the plus-Mor experiment, oocytes were exposed to $100 \mu \mathrm{m}$ Mor for $15 \mathrm{~s}$ immediately before MTSET coapplication. Current amplitudes were normalized to control responses before MTSET exposure; means ( \pm SEM) are plotted $(n=3-7)$ for each experiment. Each time course consists of 7 or 12 time points, and the curves through the data are best fits to a single exponential decay function with $\tau=34 \pm 12,167 \pm 22$, and $719 \pm 137$ s, respectively. The parameters defining the time course initial $(A)$ and asymptotic $(B)$ values, from $y=$ $A \times \exp (-t / \tau)+B$, were $A=0.50 \pm 0.06$ and $B=0.45 \pm 0.05$ for the MTSET plus ACh data; these values were then used in the other two fits to reduce the error in $\tau$.

Mor, respectively. These rates are consistent with those found for MTS modification of other cysteine-substituted nAChRs, under pseudo-first-order conditions (Lyford et al., 2003; Hsiao et al., 2006). Mor also decreased the rate of modification of $\alpha 3 \beta 2 \mathrm{~T} 150 \mathrm{C}$ by $100 \mu \mathrm{M}$ MTSEA, giving time constants of $9 \pm 1 \mathrm{~s}$ in the absence of Mor and $16 \pm 2 \mathrm{~s}$ in the presence of Mor (data not shown; $n=3,4)$. In other experiments, we determined that the rates of modification depended on the concentration of MTS reagent, as expected, but that the final extent of decrease (at long times) depended on neither MTS concentration nor the presence of agonist or modulator, consistent with these reactions involving covalent modification (irreversible under these conditions). Also as expected, the rates of change for currents evoked by $\mathrm{ACh}, \mathrm{ACh}$ plus Mor, or Mor alone were the same when measured under identical conditions.

Considering that most of our experiments used $100 \mu \mathrm{M}$ MTS reagents and our standard application was a cumulative 2 min exposure $\left(>10\right.$ half-times based on our measurements of $t_{1 / 2} \sim$ $10 \mathrm{~s}$ under these conditions), reactions were most likely complete in those cases. It is noteworthy that under conditions in which MTS modification was not too fast (lower limit of time constant $\sim 10$ s with our methods), coapplication with ACh increased the reaction rate. In contrast, coapplication of Mor slowed the rate. These results suggest that the conformational changes associated with channel gating alter the accessibility of these residues.

\section{MTS reduces Mor-evoked currents}

The MTS effects on Mor potentiation of four $\beta(+) / \alpha(-)$ interface mutants gives strong support for our hypothesis that these residues contribute to the Mor binding site. We therefore tested
Table 2. Characteristics of Mor-evoked responses

\begin{tabular}{lclll}
\hline & $\mathrm{EC}_{50}(\mu \mathrm{m})$ & $n_{\mathrm{H}}$ & $E_{\max }{ }^{a}$ & \\
\hline$\alpha 3 \beta 2 \mathrm{wt}^{b}$ & $20 \pm 2$ & $3.1 \pm 1.6$ & 0.2 & $(4 ; 2)$ \\
$\alpha 3 \mathrm{~T} 115 \mathrm{C} \beta 2$ & $30 \pm 2$ & $1.4 \pm 0.1$ & $0.29 \pm 0.01$ & $(6 ; 2)$ \\
$\alpha 3 \beta 2 \mathrm{~T} 150 \mathrm{C}$ & $26 \pm 1$ & $2.3 \pm 0.2$ & $0.33 \pm 0.04$ & $(5 ; 1)$ \\
$\alpha 3 \beta 2 \mathrm{~S} 148 \mathrm{C}$ & $110 \pm 40$ & $1.4 \pm 0.5$ & $0.36 \pm 0.05$ & $(3 ; 1)$ \\
$\alpha 3 \beta 2 \mathrm{~S} 192 \mathrm{C}$ & $20 \pm 6$ & $1.8 \pm 0.7$ & $0.08 \pm 0.01$ & $(5 ; 1)$ \\
$\alpha 3 \beta 2 \mathrm{~T} 193 \mathrm{C}$ & $20 \pm 3$ & $1.7 \pm 0.3$ & $0.24 \pm 0.1$ & $(11 ; 1)$ \\
$\alpha 3 \mathrm{~A} 106 \mathrm{C} \beta 2$ & $62 \pm 11$ & $2.1 \pm 0.7$ & $0.56 \pm 0.05$ & $(5 ; 1)$ \\
$\alpha 3 \mathrm{~S} 161 \mathrm{C} \beta 2$ & & & &
\end{tabular}

Values are means \pm SEM. In the last column, the number of oocytes tested and the number of donors, respectively, are given in parentheses. wt, Wild type.

${ }^{a} E_{\max }$, the maximum response at saturating concentrations of Mor, was measured relative to the response elicited by ACh alone (as an internal control), using an $[\mathrm{ACh}] \sim \mathrm{EC}_{50}$ as indicated in Table 1.

${ }^{b}$ Data from Wu et al. (2008)

whether MTS treatment could change currents evoked by Mor alone. We first studied the concentration-response relationships using Mor as the agonist; these results are shown in Table 2. As with the wild-type nAChR, Mor was a weak partial agonist, evoking currents at saturating concentrations that were $<25 \%$ of the currents evoked by ACh at a saturating concentration. The range of $E_{\max }$ values was $0.08-0.56$ (relative to an internal control of [ACh] approximately $\mathrm{EC}_{50}$ ), which bracket that for wild type (0.20). These apparent differences in the $E_{\max }$ values for the mutants may well be real, but because the currents were typically very small ( $\leq 200 \mathrm{nA}$ ) and these were all separate experiments, we hesitate to interpret the differences. Similarly, the fitted values of $\mathrm{EC}_{50}$ and $n_{\mathrm{H}}$ for the mutants were about the same as those for the wild type, with the exception of the $\mathrm{EC}_{50}$ for $\alpha 3 \beta 2 \mathrm{~S} 148 \mathrm{C}$. Of note, the Hill coefficient for activation by Mor in all cases was substantially larger than that for activation by ACh $(\sim 2.0$ vs $\sim 0.75)$ (Tables 1,2 ). On the whole, these results also suggest that these cysteine substitutions alone do not greatly impact the function of the receptor.

We next measured the effects of MTS on Mor-evoked currents of $\alpha 3 \beta 2 \mathrm{~T} 150 \mathrm{C}$ receptors, using a variety of modifying reagents. Figure 7 shows Mor concentration-response curves before (filled symbols) and after (open symbols) the treatments. MTSET, which carries a permanent positive charge, and MTSEA, which should be predominantly protonated at $\mathrm{pH} 7.2$, reduced the maximum Mor-evoked current by $75-80 \%$ without changing the potency. The neutral and aromatic MTSBn decreased the potency fourfold and the efficacy by $45 \%$. These changes in efficacy are significant and can be interpreted because of the pre/post design of the experiment. Treatment with bromoacetylcholine (BrACh) appears to have had very little effect. Importantly, in the experiments with the three MTS reagents, the decrease in AChevoked currents, measured as controls, was the same: values of $I_{\text {post }} / I_{\text {pre }}$ were $0.51 \pm 0.13,0.40 \pm 0.02$, and $0.48 \pm 0.06$ for MTSET, MTSEA, and MTSBn treatments, respectively $(n=3-5)$ (supplemental Table $1 B$, available at www.jneurosci.org as supplemental material). There were no appreciable changes in these currents or potentiation in the BrACh experiment. Therefore, at least for these three MTS reagents, perturbation of the ACh-site functions does not depend on the nature of the MTS reagent, whereas perturbation of the Mor-site functions does.

As demonstrated in Figure 8, treatment with MTSET alone also reduced currents evoked by Mor alone for the $\alpha 3$ T115C $\beta 2$ receptor. The treatment had no effect on Mor potency, with $\mathrm{EC}_{50}$ $=30 \mu \mathrm{M}$ before and after treatment. However, after exposure to $100 \mu \mathrm{M}$ MTSET alone, the Mor efficacy decreased by $66 \%$ ( $E_{\max }$ $=0.3$ pre vs 0.1 post). In this experiment, MTSET treatment left 


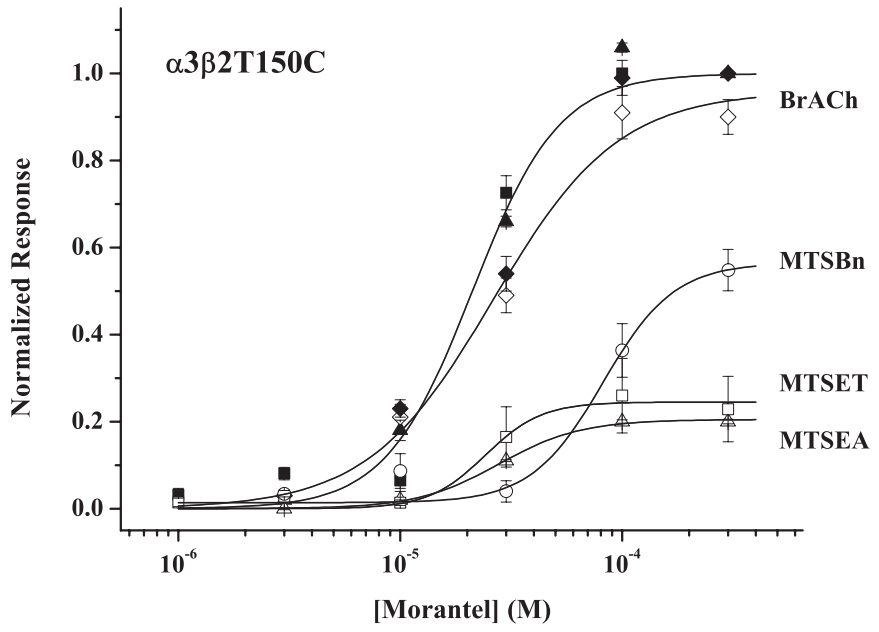

Figure 7. MTS reagents reduce Mor-evoked currents of $\alpha 3 \beta 2 \mathrm{~T} 150 \mathrm{C}$ receptors. MTS reagents (100 $\mu \mathrm{m}$ ) were applied to $\alpha 3 \beta 2 \mathrm{~T} 150 \mathrm{C}$ receptors in four $30 \mathrm{~s}$ doses separated by a $100 \mathrm{~s}$ wash period; $\mathrm{BrACh}(100 \mu \mathrm{m})$ was applied in the same manner. Filled symbols indicate pretreatment control responses, and open symbols are posttreatment. Each data set is normalized to the pretreatment $300 \mu \mathrm{m}$ Mor response; in addition, each experiment included a control $300 \mu \mathrm{m}$ ACh response (pre and post), for which $I_{300 \mu \mathrm{M} \text { Mor }} / I_{300 \mu \mathrm{M} \text { ACh }}$ (pre) was $0.14 \pm 0.01(n=17)$. Fitting parameters for each data set are as follows $\left(\mathrm{EC}_{50}\right.$ in $\left.\mu \mathrm{M}, n_{\mathrm{H}}, E_{\mathrm{max}}\right)$ : control: $20 \pm 2,2.2 \pm$ 0.4, 1.00; BrACh: $30 \pm 5,1.5 \pm 0.4,0.96 \pm 0.07$; MTSBn: $80 \pm 20,2.7 \pm 1.5,0.56 \pm 0.07$; MTSET: $20 \pm 4,3.4 \pm 1.9,0.24 \pm 0.02 ;$ MTSEA: $30 \pm 1,2.3 \pm 0.3,0.20 \pm 0.01 . n=5$, except for MTSEA $(n=3)$.

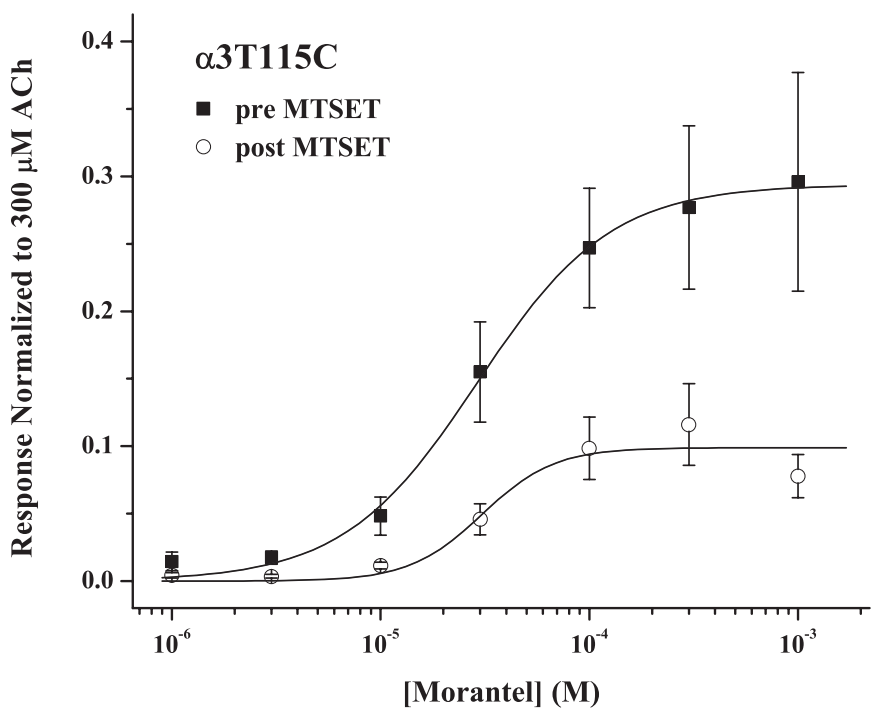

Figure 8. MTSET reduces Mor-evoked currents of $\alpha 3 \mathrm{~T} 115 \mathrm{C} \beta 2$ receptors. MTSET (100 $\mu \mathrm{M})$ was applied to $\alpha 3 \mathrm{~T} 115 \mathrm{C} \beta 2$ receptors in four 30 s doses. Means ( \pm SEM) for $I_{\text {Mor }} / I_{300 \mu \mathrm{m} \mathrm{ACh}}$ are plotted versus the concentration of Mor ( $n=3-7 ; 2$ donors); all responses were normalized to that of $300 \mu \mathrm{m} \mathrm{ACh}$, before the MTSET modification. Fits gave the following: pre-MTSET: $\mathrm{EC}_{50}=30 \pm 2 \mu \mathrm{M}, n_{\mathrm{H}}=1.4 \pm 0.1, E_{\max }=0.29 \pm 0.01$; post-MTSET: $\mathrm{EC}_{50}=30 \pm 8 \mu \mathrm{m}$, $n_{\mathrm{H}}=2.2 \pm 1.4, E_{\max }=0.10 \pm 0.01$.

$I_{\mathrm{ACh}}$ unchanged but reduced $I_{\mathrm{ACh}+\text { Mor }}$ by $32 \pm 9 \%$ and decreased potentiation by $31 \pm 8 \%(p=0.04 ; n=6)$. As was the case for the $\alpha 3 \beta 2 \mathrm{~T} 150 \mathrm{C}$ mutant, the effects of MTS treatment on ACh- and Mor-mediated behavior of the $\alpha 3 \mathrm{~T} 115 \mathrm{C} \beta 2$ receptor are quantitatively different.

\section{Discussion}

We have demonstrated in this study that four residues in the $\beta(+) / \alpha(-)$ interface of neuronal nAChRs, two on each side, decrease agonist and allosteric modulator functions when substituted with cysteine and treated with MTS compounds. MTS reagents primarily reduce evoked currents, and magnitudes of the MTS effects on the ACh- and Mor-mediated responses differ quantitatively from one another. Importantly, both Mormediated responses $\left(I_{\mathrm{ACh}+\mathrm{Mor}}\right.$ and $\left.I_{\mathrm{Mor}}\right)$ are always reduced for the two mutants we studied in greatest detail $(\alpha 3 \mathrm{~T} 115 \mathrm{C} \beta 2$ and $\alpha 3 \beta 2 \mathrm{~T} 150 \mathrm{C}$ ), even under conditions in which $I_{\mathrm{ACh}}$ is not affected. Furthermore, Mor can inhibit MTS reactivity. We argue below that the four residues $\alpha 3 \mathrm{~A} 106, \alpha 3 \mathrm{~T} 115, \beta 2 \mathrm{~T} 150$, and $\beta 2 S 192$ are near or in the Mor binding site, which for simplicity we take to account for both potentiation and partial agonist activities.

\section{The alternate interface model}

We hypothesized that Mor binds to the $\beta(+) / \alpha(-)$ interface for several reasons. In previous work, we demonstrated that Mor does not act at the canonical (ACh) ligand binding site, the $\alpha(+) /$ $\beta(-)$ interface, because Mor-evoked currents were inhibited noncompetitively by dihydro- $\beta$-erythroidine and low concentrations of Mor still potentiated in the presence of saturating concentrations of agonist (Wu et al., 2008). The overall homology of all $\mathrm{nAChR}$ subunits and their pinwheel arrangement within a pentameric complex yield pockets in which ligands could potentially bind, at all subunit interfaces (Brejc et al., 2001; Sallette et al., 2004; Hansen and Taylor, 2007). Furthermore, of the two tryptophan and three tyrosine residues known to stabilize ligand-receptor binding through $\pi$-cation interactions (Zhong et al., 1998; Karlin, 2002), only tyrosine 190 ( $\alpha 1$ numbering) is missing in the $\beta(+) / \alpha(-)$ interface of $(\alpha 3)_{2}(\beta 2)_{3}$ receptors (Fig. $1 B)$. Last, Mor potentiation of $\mathrm{nAChRs}$ is similar to benzodiazepine potentiation of $\mathrm{GABA}_{\mathrm{A}}$ receptors, and those drugs bind at the nonagonist, alternate $\alpha(+) / \gamma(-)$ interface (Buhr and Sigel, 1997).

The residues of $\alpha 3 \beta 2$ receptors that significantly decrease Mor activities when substituted with cysteines and chemically modified are homologous to known cys-loop family binding site residues: (1) Lee and Sine (2004) demonstrated that the $\alpha 1 \mathrm{~T} 150$ residue in muscle-type receptors, homologous to the neuronal $\beta 2 \mathrm{~T} 150$, has a role in ACh binding, most likely through interactions with a conserved aspartate in the neighboring subunit, which perhaps contributes to the optimal positioning of the highly conserved W149. (2) $\alpha 3$ A106 is immediately adjacent to a position in the $\mathrm{GABA}_{\mathrm{A}} \gamma 2$ subunit (M130) involved in benzodiazepine binding (Buhr and Sigel, 1997). (3) $\alpha 3$ T115 occurs within a stretch of residues of rather variable composition across $\mathrm{nAChR}$ subunits, but which contains residues such as $\gamma \mathrm{Y} 117$ in the $(-)$ side of the canonical interface that are important for ligand binding and specificity (Chiara et al., 1999; Sine et al., 2002 , and references therein). (4) $\beta 2 S 192$ and $\beta 2 \mathrm{~T} 193$ lie within a region homologous to the $\alpha(+)$ C loop in which are found the vicinal cysteines known to play a role in receptor activation (for review, see Karlin, 2002; Sine, 2002). This region in $\beta 2$ is three amino acids shorter than $\alpha$ subunit sequences between the highly conserved 174GEW176 and 200DITY203 ( $\alpha 1$ numbering) sequences; therefore, precise homologous correspondence is difficult to assign. Nonetheless, S192 and T193 are predicted to be near the system of aromatic residues forming this putative binding pocket (Sallette et al., 2004).

In light of the demonstrated importance of the aforementioned residues, it is surprising that $\beta 2 \mathrm{~S} 148 \mathrm{C}, \alpha 3 \mathrm{~S} 161 \mathrm{C}$, and $\beta 2 \mathrm{~T} 193 \mathrm{C}$ showed no MTS effects. S161 may be too far away from, or the local structure of the highly variable F loop region directs it 
away from, the pocket. Similarly, the folding of this " $\mathrm{C}$ loop" region of the $\beta$ subunit may make S148 and T193 reagent inaccessible.

In addition to the cysteine substitution approach in this study, we are conducting "traditional" mutation studies to explore the specificity of the Mor site, choosing substitutions based on the lack of Mor potentiation in $\alpha 4 \beta 2$ receptors. For example, $\alpha 3$ E113R completely abolishes Mor potentiation (making it $\alpha 4$ like), whereas $\alpha 3 \mathrm{~K} 109 \mathrm{~F}$ maintains the wild-type $\alpha 3 \beta 2$ Mor potentiation characteristics (R. E. Laureijs and M. M. Levandoski, unpublished observation). All told, mutational analysis of the $\beta(+) / \alpha(-)$ interface indicates that it constitutes the Mor binding site.

\section{Allostery and the Mor binding site}

Independent of the issue of locating Mor binding on $\alpha 3 \beta 2$ receptors, we have demonstrated a role for several specific residues in the allosteric behavior of these nAChRs. The $\beta(+) / \alpha(-)$ interface residues we studied are not in the accepted, canonical agonist/competitive antagonist site (Arias, 2000; Sine, 2002). Therefore, these residues play no direct role in agonist binding. Nonetheless, the residues $\alpha 3 \mathrm{~T} 115$ and $\alpha 3$ S161 change the ACh potency when substituted with cysteine (Table 1). More importantly, ACh-evoked currents and concentration-response relationships are altered when the cysteine mutants are modified with MTS reagents (Figs. 2-5). These findings are consistent with previous demonstrations in neuronal nAChRs of the allosteric communication between subunit interfaces for zinc potentiation of $\alpha 4$-containing receptors (Hsiao et al., 2006, 2008; Moroni et al., 2008 ) and for a chimeric $\beta 4$ subunit in which a toxin-binding pharmatope was inserted (Sanders and Hawrot, 2004). Our results indicate that the $\beta(+) / \alpha(-)$ interface participates in the conformational changes accompanying channel gating, because agonist efficacy is changed by MTS treatment (Fig. 4) and gating changes can manifest as potency changes at the macroscopic level (Colquhoun, 1998).

Because we observe the aforementioned allosteric effects on ACh activation, it is a formal possibility that Mor binds elsewhere yet interacts at a distance with the targeted $\beta(+) / \alpha(-)$ residues. As a related concern, we might have expected MTS modification to consistently change potency as well as efficacy of Mor activation (compare Fig. 7); the lack of such consistency underscores the inherent complexity of dissecting binding from gating effects (Colquhoun, 1998). However, our data support the simpler interpretation that this interface constitutes the Mor binding site. In general, the effects of chemical modification on ACh-evoked currents differ from the effects on ACh/Mor- and Mor-evoked currents (Figs. 2, 5, 7); this alone does not preclude the possibility that Mor acts from a site other than the $\beta(+) / \alpha(-)$ interface. However, Mor-mediated responses were always reduced for the two mutants we studied in detail; in particular, for the $\alpha 3 \mathrm{~T} 115 \mathrm{C} \beta 2$ receptor, certain conditions of MTS treatment had no effect on $I_{\mathrm{ACh}}$ but decreased markedly $I_{\mathrm{ACh}+\text { Mor }}$ and $I_{\mathrm{Mor}}$.

Most importantly, ACh and Mor impact MTS modification in opposite ways. As shown in Figure 6, the presence of ACh accelerates MTS modification of $\alpha 3 \mathrm{~T} 115 \mathrm{C} \beta 2$. This was also true in the standard, fixed time-point experiments with $\alpha 3 \mathrm{~A} 106 \mathrm{C} \beta 2$, $\alpha 3 \beta 2$ S192C, and $\alpha 3$ T115C $\beta 2$ receptors (compare Fig. 3). Conversely, the presence of Mor inhibits this reaction (Fig. 6), a result found for both $\alpha 3$ T115C $\beta 2$ and $\alpha 3 \beta 2$ T150C. Functionally, both ACh and Mor promote channel opening in $\alpha 3 \beta 2$ receptors, and it is reasonable to assume that the subunit-level and global conformational changes accompanying opening are independent of the agonist (or modulator) identity. We interpret, as have others (Wagner and Czajkowski, 2001; Lyford et al., 2003), that condition-dependent MTS reactivity differences indicate conformational state differences. If ACh and Mor binding lead to the same global motions in the receptor, then their different effects on MTS reactivity must arise from differences in the local environment. Consequently, that Mor inhibits MTS reactivity for these cysteine mutants, in addition to MTS modification decreasing Mor-mediated currents, seems possible only if Mor and MTS colocalize on the receptor. The homology of the $\mathrm{nAChR}$ residues we studied to accepted constituents of cys-loop receptor binding sites and the many direct effects observed for MTS modification of these residues are consistent with the hypothesis that Mor binds at the $\beta(+) / \alpha(-)$ interface of $\alpha 3 \beta 2$ receptors.

\section{Partial agonism revisited and new drug targets}

Our demonstration that Mor binds at the $\beta(+) / \alpha(-)$ subunit interface has two important implications for the nicotinic receptor field. First, that Mor, as a partial agonist, acts from a site other than the canonical agonist site suggests a general role of non- $\alpha$ subunits in the allosteric movements within the nAChR that constitute the (intramolecular) transfer of information from binding to channel gating (cf. Lee and Sine, 2005). Such putative intramolecular pathways for gating seem logical in the context of homopentamers such as $\alpha 7$, with five potential agonist sites (Palma et al., 1996), in which the $\alpha$ subunits form both $(+)$ and $(-)$ sides of the binding interface. The phenomenon of partial agonism (Hogg and Bertrand, 2007) should be reexamined in light of the possibilities of action from noncanonical sites and a role for non- $\alpha$ subunits in gating.

Second, noncanonical nAChR interfaces offer diverse, potential new binding sites for drug targeting as well as alternatives for generating specificity. Maelicke and Albuquerque (2000) lauded allosteric modulators for their capacity to coordinate both temporally and spatially with endogenous cholinergic systems. Of particular interest are modulators that are very poor agonists alone; indeed, recent advances indicate the importance of this class of nicotinic compounds (Bertrand and Gopalakrishnan, 2007). Although known nAChR-positive allosteric modulators are structurally diverse, it is possible that binding at alternate interfaces is a common underpinning, especially for ACh- and nicotine-like amines such as galantamine (cf. Akk and Steinbach, 2005). Establishing the generality of alternate interfaces as modulator sites coupled with elucidating the composition of native receptors should lead to the rational design of specific allosteric modulators.

\section{References}

Akk G, Steinbach JH (2005) Galantamine activates muscle-type nicotinic acetylcholine receptors without binding to the acetylcholine-binding site. J Neurosci 25:1992-2001.

Arias HR (2000) Localization of agonist and competitive antagonist binding sites on nicotinic acetylcholine receptors. Neurochem Int 36:595-645.

Arias HR, Bhumireddy P, Spitzmaul G, Trudell JR, Bouzat C (2006) Molecular mechanisms and binding site location for the noncompetitive antagonist crystal violet on nicotinic acetylcholine receptors. Biochemistry 45:2014-2026.

Bertrand D, Gopalakrishnan M (2007) Allosteric modulation of nicotinic acetylcholine receptors. Biochem Pharmacol 74:1155-1163.

Bertrand D, Cooper E, Valera S, Rungger D, Ballivet M (1991) Electrophysiology of neuronal nicotinic acetylcholine receptors expressed in Xenopus oocytes following nuclear injection of genes of cDNAs. Methods Neurosci 4:174-193.

Birks J (2006) Cholinesterase inhibitors for Alzheimer's disease. Cochrane Database Syst Rev 1:CD005593. 
Brejc K, van Dijk WJ, Klaassen RV, Schuurmans M, van Der Oost J, Smit AB, Sixma TK (2001) Crystal structure of an ACh-binding protein reveals the ligand-binding domain of nicotinic receptors. Nature 411:269-276.

Buhr A, Sigel E (1997) A point mutation in the $\gamma 2$ subunit if $\gamma$-aminobutyric acid type A receptors results in altered benzodiazepine binding site specificity. Proc Natl Acad Sci U S A 94:8824-8829.

Celie PH, van Rossum-Fikkert SE, van Dijk WJ, Brejc K, Smit AB, Sixma TK (2004) Nicotine and carbamylcholine binding to nicotinic acetylcholine receptors as studied in AChBP crystal structures. Neuron 41:907-914.

Chavez-Noriega LE, Crona JH, Washburn MS, Urrutia A, Elliott KJ, Johnson EC (1997) Pharmacological characterization of recombinant human neuronal nicotinic acetylcholine receptors $\mathrm{h} \alpha 2 \beta 2, \mathrm{~h} \alpha 2 \beta 4 \mathrm{~h}, \mathrm{~h} \alpha 3 \beta 2$, $\mathrm{h} \alpha 3 \beta 4, \mathrm{~h} \alpha 4 \beta 2$, h $\alpha 4 \beta 4$, and $\mathrm{h} \alpha 7$ expressed in Xenopus oocytes. J Pharmacol Exp Ther 280:346-356.

Chiara DC, Xie Y, Cohen JB (1999) Structure of the agonist-binding sites of the Torpedo nicotinic acetylcholine receptor: affinity-labeling and mutational analyses identify $\gamma$ tyr- $111 / \delta$ arg-113 as antagonist affinity determinants. Biochemistry 38:6689-6698.

Cohen BN, Figl A, Quick MW, Labarca C, Davidson N, Lester HA (1995) Regions of $\beta 2$ and $\beta 4$ responsible for differences between the steady state dose-response relationships of the $\alpha 3 \beta 2$ and $\alpha 3 \beta 4$ neuronal nicotinic receptors. J Gen Physiol 105:745-764.

Colquhoun D (1998) Binding, gating, affinity and efficacy: the interpretation of structure-activity relationships for agonists and of the effects of mutating receptors. Br J Pharmacol 125:924-947.

Curtis L, Buisson B, Bertrand S, Bertrand D (2002) Potentiation of human $\alpha 4 \beta 2$ neuronal nicotinic acetylcholine receptor by estradiol. Mol Pharmacol 61:127-135.

Hansen SB, Taylor P (2007) Galanthamine and non-competitive inhibitor binding to ACh-binding protein: evidence for a binding site on nonalpha-subunit interfaces of heteromeric neuronal nicotinic receptors. J Mol Biol 369:895-901.

Harvey SC, Luetje CW (1996) Determinants of competitive antagonist sensitivity on neuronal nicotinic receptor beta subunits. J Neurosci 16:3798-3806.

Hogg RC, Bertrand D (2007) Partial agonists as therapeutic agents at neuronal nicotinic acetylcholine receptors. Biochem Pharmacol 73:459-468.

Hsiao B, Mihalak KB, Repicky SE, Everhart D, Mederos AH, Malhotra A, Luetje CW (2006) Determinants of zinc potentiation on the $\alpha 4$ subunit of neuronal nicotinic receptor. Mol Pharmacol 69:27-36.

Hsiao B, Mihalak KB, Magleby KL, Luetje CW (2008) Zinc potentiates neuronal nicotinic receptors by increasing burst duration. J Neurophysiol 99:999-1007.

Hurst RS, Hajós M, Raggenbass M, Wall TM, Higdon NR, Lawson JA, Rutherford-Root KL, Berkenpas MB, Hoffman WE, Piotrowski DW, Groppi VE, Allaman G, Ogier R, Bertrand S, Bertrand D, Arneric SP (2005) A novel allosteric modulator of the $\alpha 7$ neuronal nicotinic acetylcholine receptor: in vitro and in vivo characterization. J Neurosci 25:4396-4405.

Jensen AA, Frølund B, Liljefors T, Krogsgaard-Larsen P (2005) Neuronal nicotinic acetylcholine receptors: structural revelations, target identifications, and therapeutic inspirations. J Med Chem 48:4705-4745.

Karlin A (2002) Emerging structure of the nicotinic acetylcholine receptors. Nat Rev Neurosci 3:102-114.

Karlin A, Akabas MH (1998) Substituted-cysteine accessibility method. Methods Enzymol 293:123-145.

Lee WY, Sine SM (2004) Invariant aspartic acid in muscle nicotinic receptor contributes selectively to the kinetics of agonist binding. J Gen Physiol 124:555-567.
Lee WY, Sine SM (2005) Principal pathway coupling agonist binding to channel gating in nicotinic receptors. Nature 438:243-247.

Levandoski MM, Piket B, Chang J (2003) The anthelmintic levamisole is an allosteric modulator of human neuronal nicotinic acetylcholine receptors. Eur J Pharmacol 471:9-20.

Lyford LK, Sproul AD, Eddins D, McLaughlin JT, Rosenberg RL (2003) Agonist-induced conformational changes in the extracellular domain of $\alpha 7$ nicotinic acetylcholine receptors. Mol Pharmacol 64:650-658.

Maelicke A, Albuquerque EX (2000) Allosteric modulation of nicotinic acetylcholine receptors as a treatment strategy for Alzheimer's disease. Eur J Pharmacol 393:165-170.

Martin RJ (1997) Modes of action of anthelmintic drugs. Vet J 154:11-34.

Moroni M, Vijayan R, Carbone A, Zwart R, Biggin PC, Bermudez I (2008) Non-agonist-binding subunit interfaces confer distinct functional signatures to the alternate stoichiometries of the $\alpha 4 \beta 2$ nicotinic receptor: an $\alpha 4-\alpha 4$ interface is required for $\mathrm{Zn}^{2+}$ potentiation. J Neurosci 28:6884-6894.

Nirthanan S, Garcia G 3rd, Chiara DC, Husain SS, Cohen JB (2008) Identification of binding sites in the nicotinic acetylcholine receptor for TDBzletomidate, a photoreactive positive allosteric effector. J Biol Chem 283:22051-22062.

Palma E, Bertrand S, Binzoni T, Bertrand D (1996) Neuronal nicotinic $\alpha 7$ receptor expressed in Xenopus oocytes presents five binding sites for methyllycaconitine. J Physiol 491:151-161.

Paterson D, Nordberg A (2000) Neuronal nicotinic receptors in the human brain. Prog Neurobiol 61:75-111.

Romanelli MN, Gualtieri F (2003) Cholinergic nicotinic receptors: competitive ligands, allosteric modulators, and their potential applications. Med Res Rev 23:393-426.

Sallette J, Bohler S, Benoit P, Soudant M, Pons S, Le Novere N, Changeux JP, Corringer JP (2004) An extracellular protein microdomain controls upregulation of neuronal nicotinic acetylcholine receptors by nicotine. J Biol Chem 279:18767-18775.

Sanders T, Hawrot E (2004) A novel pharmatope tag inserted into the $\beta 4$ subunit confers allosteric modulation to neuronal nicotinic receptors. J Biol Chem 279:51460-51465.

Sine SM (2002) The nicotinic receptor ligand binding domain. J Neurobiol 53:431-446.

Sine SM, Wang HL, Bren N (2002) Lysine scanning mutagenesis delineates structural model of the nicotinic receptor ligand binding domain. J Biol Chem 277:29210-29223

Siu EC, Tyndale RF (2007) Non-nicotinic therapies for smoking cessation. Annu Rev Pharmacol Toxicol 47:541-564.

Timmermann DB, Grønlien JH, Kohlhaas KL, Nielsen EØ, Dam E, Jørgensen TD, Ahring PK, Peters D, Holst D, Christensen JK, Malysz J, Briggs CA Gopalakrishnan M, Olsen GM (2007) An allosteric modulator of the $\alpha 7$ nicotinic acetylcholine receptor possessing cognition-enhancing properties in vivo. J Pharmacol Exp Ther 323:294-307.

Unwin N (2005) Refined structure of the nicotinic acetylcholine receptor at 4 Å resolution. J Mol Biol 346:967-989.

Wagner DA, Czajkowski C (2001) Structure and dynamics of the GABA binding pocket: a narrowing cleft that constricts during activation. J Neurosci 21:67-74.

Wu TY, Smith CM, Sine SM, Levandoski MM (2008) Morantel allosterically enhances channel gating of neuronal nicotinic acetylcholine $\alpha 3 \beta 2$ receptors. Mol Pharmacol 74:466-475.

Zhong W, Gallivan JP, Zhang Y, Li L, Lester HA, Dougherty DA (1998) From $a b$ initio quantum mechanics to molecular neurobiology: a cation-pi binding site in the nicotinic receptor. Proc Natl Acad Sci U S A 95:12088-12093. 